\title{
Putting Derivatives in their Proper Place
}

\author{
Tom Valentine
}

T

The rapid expansion of derivatives trading has attracted a wave of criticism and led to the expression of a number of concerns. These expressions have ranged from careful analyses of the risks inherent in the instruments and of the changes in the regulatory framework necessary to deal with them, to wild predictions that derivatives will draw us to our economic doom. The fear of derivatives arises from a number of beliefs: that they have increased the volatility of financial markets; that they have created systemic instability so that a disturbance originating in one part of the world will be transmitted to other parts, possibly in a magnified form; and that losses from derivatives trading will lead to the failure of a major bank, triggering a domino effect on other banks trading with it. But, in reality, derivatives can make a very useful contribution to reducing the risk of funancial transactions.

This article explains how derivatives work, assesses the concerns about them listed above, and defines the boundaries of their safe and useful application. The first step is to describe derivatives and to indicate their relationship with the markets for the securities on which they are based.

\section{Derivative Instruments}

Derivatives are financial instruments or contracts that derive their value from the prices of underlying securities, commodities or indices. For example, futures or options on bills, gold and a share-price index depend for their value on, respectively, the price of bills, the gold price and the value of the share-price index. In many cases the value of the derivative depends on the price of the underlying product because it can actually be delivered in settlement of the contract. In other cases there is a cash setthement the magnitude of which depends on the difference between the price at which the derivative was obtained and the price of the underlying product on settlement date. A cash settlement is necessary when the value of the derivative depends on a notional index, such as a share-price index, or when the underlying commodity is in short supply, so making it possible to 'squeeze' the market if a physical settlement is required.

Derivatives fall into two classes: 'exchange traded' and 'over-the-counter'. Exchange-traded derivatives are priced through some form of bidding process on an organised exchange (market). The availability of a market means that holdings of derivatives ('positions') can be adjusted easily. They can also be revalued (marked to

Tom Valentine is Dean of Commerce and Professor of Banking and Finance at the University of Western Sydney (Nepean). 
market) easily because a market price exists at all times. In order to ensure the liquidity of the market, however, it is necessary to strictly limit the range of contracts available.

Over-the-counter products are contracts between two parties. Their prices are determined by negotiation, but they must be set close to those of similar instruments, including exchange-traded instruments. The terms of these contracts can be tailored to the requirements of the parties. As over-the-counter derivatives are not homogenous, there may not be a liquid market for them or a continuously quoted market price that can be used to mark positions to market. The forward foreign-exchange market, which is very liquid and which publishes prices continuously, shows that this is not always the case.

Exchange-traded and over-the-counter instruments also differ in the credit risk borne by buyers and sellers. Holders of exchange-traded products are exposed to the credit of the exchange's clearing house, whereas each party to an over-the-counter contract is exposed to the credit standing of the other.

Examples of derivatives include:

- forward foreign-exchange contracts that allow the parties to fix the exchange rate at which a future foreign-currency transaction is carried out;

- commodity futures (contracts traded in the futures exchange) and forwards (overthe-counter equivalents of futures) that perform the same function for commodity traders;

- interest-rate futures and Forward Rate Agreements (FRAs) that fix the interest rate on a future loan or investment;

- swaps that allow participants to exchange interest-rate obligations, such as exchanging a floating-rate obligation for one that is fixed; and

- options that give holders the right but not the obligation to purchase (a call option) or sell (a put option) the underlying security at a nominated price.

Almost everybody has had experience of some type of derivative. A fixed-rate mortgage is equivalent to a floating-rate mortgage plus an interest-rate futures or forward contract. A 'capped' mortgage is a type of option. At the other end of the spectrum, financial institutions are continually introducing more and more sophisticated ('exotic') products. Banks are able to offer these consumer products only because they can lay off (i.e. take the opposite position) the resulting interest-rate risk through wholesale derivative markets, a process usually performed through the swaps markets.

It is always possible to replicate the cash flows of a derivative by creating a joint position in two other instruments. This process can be represented by the arithmetical statement (see Smith, 1993): 


$$
A=B+C
$$

In this statement the equals sign means that in all circumstances the position in $\mathrm{A}$ generates exactly the same cash flows as the combined position in B and C. A plus sign indicates that we have a long (i.e., bought) position and a negative sign indicates a short (i.e., sold) position. For example, an investment is a long position in a security while a loan is a short position in a security.

Equation (1) can be manipulated as if it is a standard arithmetical statement. Thus

$$
\mathrm{B}=A-C
$$

indicates that the cash flows of $\mathrm{B}$ can be replicated by a position combining a long position in $\mathrm{A}$ and a short position in $\mathrm{C}$. This kind of manipulation can be used to create synthetic positions (a point illustrated below).

In order to price a derivative, we need to identify the appropriate version of (1) for it. Then the price of $A$ is determined by the total price of the combined position in $B$ and $C$. If this is not the case, an arbitrage will be possible. When equivalent products or funancial positions have different prices, arbitragers can make a riskless profit by simultaneously buying the one with the lower price and selling the one with the higher price, that is, by following the golden rule of buying low and selling high. In doing so, they push the prices closer together, thereby making the market more efficient.

For example, assume that the price of $A$ is above the combined price of $(B+C)$. Then a riskless profit can be earned by selling $A$ and using the funds so obtained to buy $(B+C)$. The profit would be riskless because the two positions produce the same cash flows in all circumstances. To look at this arbitrage in another way: the two positions would have the same present values and must therefore have the same prices, since otherwise an arbitrage opportunity would exist.

For derivatives, either $\mathrm{B}$ or $\mathrm{C}$ is the underlying product. This means that there is a close relationship between the markets for physical products and the related derivative products. A disturbance in one of these markets must be transmitted to the other because both the derivative and the underlying product must be repriced in line with (1). This relationship also indicates that the prices of derivatives are not determined in a vacuum and they are not the result of random fluctuations on a casino-like market. They depend on the price of an actual product.

An example will show how equation (1) can be applied to an actual derivative. Consider a stock-price index futures contract similar to the SPI contract traded on the Sydney Futures Exchange. This contract is settled against the all ordinaries share price index. The version of equation (1) applicable to this case is:

$$
\underset{\text { Shdex Futures }}{\text { Indice }}=\begin{aligned}
& \text { Spot Shane } \\
& \text { Position }
\end{aligned}+\text { Loan }
$$

This means that an index futures position is equivalent to a shareholding that is carried to settlement date and funded out of a loan for the holding period. If, for exam- 
ple, the price of the stock-price index contract is above the price at which a future shareholding can be obtained by buying it now and holding it to settlement date, a profitable arbitrage is available. It involves buying and holding shares (funding the holding from a loan) and selling stock-price index futures. This transaction is a standard arbitrage in the futures market, but in the context of stock-index futures the process is known as 'program trading'.

It might be asked why derivatives have been developed when they can be replicated by positions in the underlying security. One reason is that a packaged version is easier to use than a composite position. It is also likely to be cheaper in that it economises on transaction costs and will be provided at lower cost by financial institutions who can obtain favourable rates in all the markets involved. Another reason for the existence of derivatives is that they can be created even when the underlying security is in short supply or for notional measures such as price indices.

Relationship (3) provides an illustration of how derivatives can be used to create synthetic products. It can be rewritten:

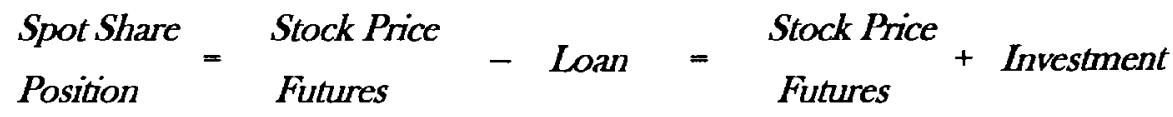

This version of the equation shows that a 'synthetic' shareholding can be constructed by combining a long position in stock-index futures with a fixed-interest investment. This approach to share investment may be preferable to the alternative of direct share investment for a number of reasons. Specifically, transactions costs are often lower in the futures market than in the slare market; the synthetic approach avoids the costs of administering the portfolio, collecting dividends, and so on; and there is no risk of loss from a company failure.

It is often easier to make offshore share investments via stock index futures (using equation (4)) than physical shares (see Jorion \& Roisenberg, 1993). In this case the fixed-interest investment can be in the domestic currency, reducing foreign-currency exposure. The futures involve lower transactions costs and less need to collect information. On the other hand, a synthetic share porffolio reflects the average performance of the market so that there is no possibility of achieving a superior performance by choosing shares that outperform the market.

Equation (4) also illustrates how a fixed-interest portfolio can be converted into a share portfolio when the fund manager believes that such a switch would be advantageous. It can easily be switched back when the fund manager's views change. If this conversion were to be done through the physical market, it would involve the sale of fixed-interest securities and the purchase of shares. The switch back would require that the transactions be reversed. 


\section{Using Derivatives}

Derivative products can be used in three ways: for speculation; for hedging exposures arising from the user's normal business activities; and for investment or borrowing through the creation of synthetic positions.

Speculation. Speculation with derivatives risks large losses. As equation (3) shows, buying a derivative is equivalent to making a leveraged investment. It is well known that such investments can result in a loss that exceeds the initial amount put up. In the case of buying a stock-index futures contract, as with any leveraged share investment, a loss will be incurred if the sharemarket falls.

But there is nothing new about this risk. Investors could construct their own leveraged share investments before share-index futures became available. Indeed, many of them still prefer the direct way of creating a leveraged share position because it allows them to pick stocks. If anything has changed, it is only the ease with which a leveraged position can be created, monitored and closed out using derivatives. This change has both advantages and disadvantages. It makes speculation more attractive, but it also makes it safer because it is easier to track and adjust positions. In particular, it is easier to close out a position that is showing a loss.

The major problem with speculation is not the appearance of a more efficient way of implementing it, but rather the factors that encourage it. In Australia the most potent of these is the incentive that the tax system provides for leveraged investment in assets. The advantages of negative gearing are explained in most popular books on personal investment.

Hedging. Derivatives can be used to hedge the financial risks that businesses incur as a result of their normal commercial activities. These risks include exposures to increasing interest rates, movements in exchange rates and falls in commodity prices. They can be hedged (or, in more familiar terms, insured against) by creating an offsetting position in derivatives.

The advantage of this approach is that it reduces the volatility of a firm's cash flows and the possibility of an insolvency. Most shareholders probably view such an outcome as desirable, but some shareholders will prefer a riskier investment if it yields a return that is high enough to compensate them for the risk. As well, shareholders may be deliberately seeking to take on the exposures inherent in a particular company. For example, an investor may buy shares in a mining company to create an exposure to the gold price and the exchange rate. Such an investor would not want the company to hedge its exposures.

One of the factors encouraging the belief that derivatives are dangerous is the large losses arising from some companies' derivative positions. Such losses have two possible sources. First, they can arise from hedge positions: in which case the losses will be offset by gains on the exposure being hedged. Second, the losses could arise from speculative positions, created by leaving exposures unhedged, by mismanaging hedges or by creating positions unrelated to the firm's underlying transactions. The latter explanation appears to apply to such cases as AWA, Proctor and Gamble 
(Falloon, 1994a) and Metallgesellschaft (Falloon, 1994b). This type of behaviour is revealed by large profits or losses from derivatives trading that is not related to the firm's core business. Large profits are as much an indication of speculative position taking as large losses: the profits could be followed by equally large losses in later years.

Similar comments can be made about fund managers. They can use derivatives to hedge exposures or they can take speculative positions in them. A pure example of the second approach is the 'hedge fund'. Originally, these funds attempted to take advantage of the volatility of share prices without taking a view on their direction. The funds would take long positions in some shares and short positions in others. They were 'hedged' only in this restricted sense: this type of position is actually highly speculative because it is possible for the shares in the long holding to go down in value and the prices of those in the short position to go up. Many of the funds now use derivatives to create high-risk-high-return positions. The losses suffered by Orange County in the United States are the most recent example of the losses that can arise from a fund of this type.

It is desirable that the spectrum of investment opportunities includes risky assets that pay a high return to cater for investors with some appetite for risk. Nevertheless, investors should be aware of the nature of the vehicle in which they are investing and of the desirability of investing only a fraction of their wealth in such vehicles. In view of the losses that have been incurred, the authorities may feel it necessary to impose disclosure requirements that reveal the nature of the risk-return trade-off involved in hedge funds.

Creating synthetic loans. As shown in the previous section, derivatives can be used to create synthetic investments or loans. This approach is often attractive to fund managers because it leads to higher returns or lower costs, reduces transaction costs, or overcomes thin physical markets. This teclinique can be used for speculative purposes. For example, a fixed-interest portfolio can be converted into a share portfolio by buying stock-index futures when it is believed that share prices will increase. Of course, this type of active management can lead to losses, but it is important to note that it can be implemented, albeit at greater cost, without using derivatives.

\section{Have Derivatives Increased Market Volatility?}

The previous sections have shown that derivatives can play an effective role in managing financial risks and reducing the cost of funancial transactions. But how should we assess the general concerns that have been raised about derivatives?

The first of these concerns is that the emergence of derivatives has increased the volatility of the market for the products underlying them. The 1987 global stockmarket crash is often cited as an example of this effect. Two types of derivative transaction are said to have aggravated the crasl: program trading and portfolio insurance.

Program trading was explained in the context of equation (3). The report on the crash of 1987 to the Chicago Mercantile Exchange (the Malkiel, Scholes and Hawke report, reproduced in Miller, 1991), describes this form of arbitrage as 'benign'. As 
with all forms of arbitrage, it ensures consistency in market prices, so that they do not give contradictory signals, and therefore makes markets more efficient.

Portfolio insurance is a mechanism for putting a floor under the value of a share portfolio while allowing the portfolio holder to benefit from increases in share prices. It involves selling shares when share prices fall and investing the funds received from the sale in fixed-interest securities. The process is reversed if share prices rise. It is a synthetic put option on the share portfolio, but it can be applied even when a put option reflecting the composition of the portfolio is not available.

It has been suggested that porfolio insurance contributed to the $1987 \mathrm{crash}$, in two ways. First, prior to the crash, rising share prices led to portfolio-insurance based purchases, which fuelled the boom. Second, portfolio insurance accentuated the crash because falling share prices led to additional sales. In fact, this type of behaviour predated the introduction of portfolio insurance. Investors have always piled into rising markets and sold into falling markets. Malkiel, Scholes and Hawke (Miller, 1991) report that portfolio-insurance driven share sales represented only 20-30 per cent of the sales that occurred on the day of the crash. The remainder was due to investors reacting in the traditional way.

One shortcoming of portfolio insurance was revealed in the crash: the floor cannot be maintained when the share price 'gaps'. A market price gaps when it changes sharply. A gap is most likely to occur between an opening price and the previous night's closing price. When gapping occurs, a loss will be suffered that cannot be offset by the interest earned on the fixed-interest investment.

Our discussion of equation (1) showed that the prices of $\mathrm{A}, \mathrm{B}$ and $\mathrm{C}$ must be consistent. When there is movement in one market, the prices in the other markets must adjust and this process could give rise to disruptions - that is, to volatility. Such disruptions are more likely if there are gaps between the markets in terms of trading conventions, trading hours, speed and cost of transactions, and so on. Malkiel, Scholes and Hawke (Miller, 1991) argue that differences in the institutional arrangements in share and futures markets increased the confusion at the time of the crash. This point emphasises the need for consistent regulation and administration of financial markets. If linked markets are subject to disparate regulatory regimes and administrative procedures, it will be easier for disruption to occur.

One reason why it is argued that derivative markets lead to instability is that the supply of derivatives is effectively unlimited. The face value of derivatives traded can exceed the amount of the underlying security available. Allegedly, the flexibility of supply allows speculative waves to push prices to higher or lower levels than would be possible in a purely physical market. Yet this flexibility could lead to derivative markets absorbing some of the volatility arising in the physical market. It should mean that pressures (such as a supply shortage) are dissipated through the derivatives market rather than through large price movements. Derivatives 'complete' financial markets.' Their existence ensures that investors can always go long on a security even if there is no physical supply. It is also possible to take a short position in a security - which

'See Strong and Walker (1987) for a formal discussion of the idea of 'completing' a market. 
might not be possible in the physical market. For example, short selling of shares was outlawed for many years. The completion of financial markets not only gives transactors access to a wider range of choices, but should also reduce volatiity.

As Lewis (1993) points out, derivatives markets provide information on market expectations. The price of the underlying product to be delivered at a future date should be approximately equal to the market's average expectation of the actual price on that date. The availability of this information is more likely to stabilise markets than to increase volatility.

So far, little empirical evidence las emerged to show that the introduction of derivatives has increased the volatility of the markets for the underlying securities. For example, Edwards (1988) concludes that there is no evidence that the introduction of stock-index futures increased the volatility of share markets. Kelly (1994) reports that there was a substantial fall in the volatility of the US equity market over the period 1990-94.

\section{Do Derivatives Promote Systemic Instability?}

A related concern is that the introduction of derivatives has created a potential for systemic instability. One aspect of this argument is that the integration of global financial markets means that a disturbance arising in one part of the world is rapidly transmitted to all other financial markets around the world. The 1987 stock-market crash demonstrates that this is the case. However, this situation was not created by the introduction of derivatives. It actually arose from funancial deregulation, which included the removal of controls on intenational capital movements. The integration arising from those reforms would have led to the transmission of shocks, such as a stock-market crash, even in the absence of derivatives.

It must also be recognised that a large part of the volatility of financial markets is a reflection of the instability of the real economies underlying these markets and that this instability arises from ineflective government policies. For example, volatility in foreign-exchange markets arises from the lack of coordination of the fiscal and monetary policies pursued in different countries. Inconsistent policies lead to frequent currency realignments, as illustrated most recently by the continuing pressure on European exchange rates. For example, if two countries have very different inflation rates, the relative value of their currencies will be subject to frequent changes. To the extent that derivatives absorb some of the volatility arising in physical markets, they will actually reduce the size of the shocks that are distributed around the world.

The concern about the impact of derivatives on systemic stability is encouraged by the view that they reduce the ability of monetary authorities to control the economy. For example, it is argued that borrowers can use derivatives to postpone the impact of higher interest rates on their business. This is true, but borrowers will recognise that interest rates have increased and react accordingly. As well, the informational content of derivative prices means that businesses receive early signals of a monetary tightening. As a result, their reaction may be speeded up rather than slowed down.

It has also been argued that derivatives can be used to sustain leveraged asset purchases in the face of increasing interest rates. However, the increased interest rates do 
create a disincentive for asset speculation via derivative purchase. Higher interest rates increase the prices of derivatives in the sense that they carry a higher premium above the spot asset price.

\section{Could Derivatives Lead to Bank Failures?}

The most important element of the concern about systemic instability is the fear that derivatives trading could lead to a failure of a large bank, which would then have a domino effect on the global banking industry. Losses could arise from the credit risk involved in the provision of derivatives, such as a possible default by a counterparty. Of more concern, however, is the possible loss arising from changes in the value of derivatives (market risk).

This fear has been heightened by an overstatement of the total value of derivatives traded. Gray (1993) attributes this overstatement to two factors. First, double counting occurs in that both sides of transactions are recorded. Second, the figures are usually expressed in terms of nominal principals, but this figure significantly overstates the bank's exposure. For example, a bank providing an FRA is exposed to the settlement amount, not to the principal covered.

The Group of Thirty (1993) rejected the possibility of a bank failure precipitating a series of secondary failures on the basis that no one derivatives provider has a large enough share of the market for a failure to cause major problems for the others. It also notes that it has so far been possible to transfer the derivatives operations of failing banks to other organisations without loss. Banks (1994:25-6) lists the comparatively modest losses that have arisen so far in derivatives trading.

The Bank of International Settlement's capital adequacy controls have forced banks to hold larger amounts of capital than before the introduction of the control. The larger equity buffer proved to be an adequate protection against the loan losses of the 1980s and 1990s, and there is no reason why it should not also be capable of performing the same function for most losses arising from derivatives trading. In addition, Wilson (1994) reports that an increasing number of banks are setting up separately capitalised companies, with higher credit ratings than their parents, to carry out derivatives activities. This has the prudential advantage that it isolates derivatives exposure from other bank activities

Nevertheless, regulators have been attracted to the idea of reducing the likelihood of a cumulative series of bank failures by ensuring that there is less chance of an initial failure and fewer interrelationships that can lead to secondary failures. The Basle Committee on Banking Supervision (1993), for example, has suggested that the capital requirements already satisfied by banks should be extended to cover the market risks they run. This control would include the market risks arising from their derivatives operations; the credit risk involved in these operations is already covered by the existing capital requirements. Daugaard and Valentine (1994) have summarised some of the problems associated with the suggested controls. One problem is that the controls protect against some forms of market risk but not others. Nor is it clear that banks, which hold substantially more capital now than they did in, say, 1985, need to hold even more capital. Increasing the capital requirement would force banks to widen 
their interest-rate margin, so reducing their competitiveness with other financial institutions and direct financing. For example, it could divert more corporate financing into the direct inter-company market. It could also lead to derivatives being provided outside the banking system, which could reduce the stability of the financial system.

The Basle Committee on Banking Supervision (1994) further suggests that the risks from banks' derivatives operations can also be controlled by supervision that ensures that they have the necessary systems in place. These include: reporting systems that allow exposures to be identified; limits or stop-loss arrangements that restrict the ability of traders to take on exposures to market risks and to individual counterparties; and the performance of 'stress' (or 'worst case') simulations that measure how banks' positions will stand up to unfavourable developments in the environment within which they trade.

Both the Group of Thirty (1993) and the Basle Committee on Banking Supervision (1994) put considerable emphasis on 'stress simulations', which do appear to be the most useful approach to measuring the risks being run in bank derivatives operations. The approach does not pretend to produce a single measure of a bank's exposures, but examines the range of problems that can arise according to the changes which occur in the environment.

The Basle Committee notes that the directors of banks must play an important role in controlling the risks taken by their organisations in their derivatives operations. This requirement can be met only if directors undergo an educational program to expand their knowledge in this area. The tendency of the legal system to expand directors' liability is likely to strongly encourage them to do so.

The recent collapse of Barings Bank underlines the need for the type of supervision suggested by the Basle Committee. The failure appears to have arisen from the absence of the most elementary internal controls. There was no separation between the trading and settlements operations of the bank, and apparently no prudential limits on the exposures created by its dealers. This lack, and otheer èvideñice (stuch as the apparent indifference to the large margin calls that the bank was forced to meet) suggest that senior management did not understand the risks involved in speculation in derivatives. In this case, even a large capital base was not able to prevent a bank failure.

\section{Conclusion}

Recent discussions of derivatives seem to have been motivated more by irrational fear than by a desire to come to a balanced judgment on their usefulness. Derivatives actually play a very useful role in allowing market participants to insure against risk and to carry out transactions more cost effectively. It is true that they can be used for speculative purposes, but these speculations are equivalent to those that were possible in physical markets before the advent of derivatives. The only additional danger arising from derivatives are that they make it easier to take such speculative positions and that users may not understand their leveraged nature.

There is little evidence to show that derivatives have made financial markets more volatile or that they have created a potential for substantial systemic instability. There 
is little need for increased regulation of derivatives markets, although the removal of inconsistencies in the treatment of different financial markets would reduce the possibility of disruptive price adjustments. Further regulation is likely to increase the global risk of derivatives trading by breaking the linkages among related markets.

A good argument can be made, however, that bank supervisors should pay some attention to the risks that arise from the derivatives activities of banks. Such supervision should ensure that banks measure these risks accurately and control them effectively. Stress simulations are an essential element in this approach. But excessively restrictive regulation would reduce the benefits that can be obtained from derivatives by making them unprofitable and possibly by reducing the stability of derivatives markets by shifting transactions from banks to less regulated intermediaries.

\section{References}

Basle Committee on Banking Supervision (1993), "The Supervisory Treatment of Market Risks", April.

_ (1994), 'Risk Management Guidelines for Derivatives', July.

Banks, E. (1994), Complex Derivatives, Probus, Chicago.

Daugaard, D. \& T. Valentine (1994), 'The Reregulation of Banking: Its Implications for the Industry and Derivatives Markets', Economic Papers 13(1): 17-40.

Edwards, F. (1988), 'Does Futures Trading Increase Stock Market Volatility?', Financial Analysts Journal 44(January-February): 63-9.

Falloon, W. (1994a), 'Courting Trouble', Risk 7(8): 32-3.

(1994b), 'MG's Trial by Essay', Risk 7(10): 28-35.

Gray, B. (1993), 'Supervision of Banks' Detivative Activities', Bulletin, Reserve Bank of Australia, August: 7-12.

Group of Thirty (1993), Denivatives: Practices and Principles - Appendix 1: Working Papers, Global Derivatives Study Group, Waslungton, July.

Jorion, P. \& L. Roisenberg (1993), 'Synthetic Intenational Diversification', The Joumal of Portfolio Management 19(2): 65-74.

Kelly, M. (1994), 'Stock Answer’, Risk 7(8): 40-3.

Lewis, M. (1993), 'Derivative Markets', Clapter 11 in M. Lewis \& R. Wallace (eds), The Australian Fnancial System, Longman Cheshire, Melboume.

Miller, M. (1991), Financial Innovations and Market Volatility, Blackwell, Oxford.

Smith, D. (1993), 'The Arithmetic of Financial Eugineering', in D. Chew (ed.), The New Corporate Fr nance: Where Theory Meets Practice, McGraw-Hill, New York. 


\section{Tom Valentine}

Strong, N. \& M. Walker (1987), Information and Capial Markets, Blackwell, Oxford.

Wilson, D. (1994), 'In Good Company', Risk 7(8): 35-9.

The author is grateful to two referees and the Editor for their comments on an earlier version of the paper. 